\title{
Enhance Marketing Services and Goods by Managing the Resources
}

\author{
Jawaher Alqahtani \\ Information Systems Department, Faculty of Computing \&Information Technology, \\ King Abdulaziz University, Jeddah, Saudi Arabia
}

\begin{abstract}
This paper discusses how to improve the marketing of services and products through the management of resources of various types of human and financial and other and the use of models and technology that helps in achieving this and presented some sources that refer to some types of models actually used and their impact on the work environment
\end{abstract}

Keywords: Decision Process Analysis, Customer relationship management, planning optimization, Market planning.

\section{INTRODUCTION}

Within current dynamic economic context, the use of technologies and programs that achieve development in all areas of service delivery to the client is being competitive. For example, smart marketing, quality of production and creativity in presentations and advertising. This is achieved through good planning and building marketing strategy and communication with customers, in other words, improvement of the marketing planning and strategies in the organization.

\section{THE IMPORTANCE OF MANAGING THE ORGANIZATION'S RESOURCES}

A comprehensive identification of "Marketing" would clarify it as being the group of actions taken by diversified bodies and foundations among procedural processes, aiming at the establishment, correspondence, delivery and the trading of offerings that are worthy for potential consumers, business associates as well as the community [2].The abstraction of the "Marketing" terminology is not feasible, as it would still have implicit humanitarian aspects in terms of making connections with personnel. If adequate attention is being paid to such humanitarian aspects, the business strategies would achieve a whole new level of accomplishment $[9,6]$.

The surroundings in the business world is currently hypercompetitive, different enterprises would direct its own marketing units towards the consideration of resources' management[10]. Financial managers would like to see that every single disbursement into the business is contributing directly or indirectly to the profit-boosting interest of the company. And consequently, helping their business having initial lead of the market[7]. For example, several studies have reported that a constructive proportionality is figured out to relate consumers' fulfilment and the financial growth of the business in terms of revenue boosting, and the payback of assets to be rewarding [1]. easy way to comply with the conference paper formatting requirements is to use this document as a template and simply type your text into it.

The former tie is applicable to businesses who adopts the measure of revenue growth along with cost optimization as a key performance index.[4].

Many of the researches have been focusing on the development of marketing planning and strategies through proposed models and theories to achieve efficiency and effectiveness[3]. However, besides their lack of supportive tools, so-far proposed metrics-based methods focus on marketing arrangements or particular cluster of shoppers, also formation of groups of shoppers based upon their favorable choices and familiarity with the market, purposes of buying, devotion of the shopper to keep buying from the same business year after a year and hence the buyer fulfillment of needs, and merchandise mantelpiece room [5].

More specifically, they do not examine the impact of the role of decisions process on improving marketing planning and strategies along with the allocation of the enterprises' resources in systematic manner, which is expected to have positive impact on the marketing plan in the proposed model. For instance, studying the industry of airlines, a significant progress has been achieved towards the customers' relationship management[5]. A giant volume of information about customers is being gathered, an alternative for leveraging such information to achieve good 


\title{
International Advanced Research Journal in Science, Engineering and Technology
}

\author{
Vol. 6, Issue 12, December 2019
}

distinctions among different consumer classes, many Frequent flyer Programs (FFPs) include single standard marketing technique for the whole spectrum of customers. Despite the availability of required technology, airline companies proceed to adopt imprecise models generating inaccurate approximations of consumer value, the value that is identified as the return produced by the purchasing profile of a certain consumer in response to the costs of marketing campaigns [2]

A key question in marketing development approach is: what guarantees do we have to optimize marketing planning and strategies? In general, assessing/verifying the efficiency of decision process in marketing has always been a crucial activity in enterprises[9]. It can be done through various complementary techniques (testing, formal analysis, measurement) at various levels of abstraction (requirements design and code)[11]. To adopt techniques-based approach to assess the efficiency of decision process in marketing. First, we propose a techniques-based module for optimizing the analysis of customer behaviors that accounts for the relationships among the enterprises and its customers. Then, we will develop a supportive tool that can be used to evaluate the proposed module empirically through a set of case studies collected from the marketing services literature.

\section{CONCLUSION}

Discussed and reviewed models and examples of attempts by some organizations to develop their capabilities and improve their efficiency through the management of existing resources and improve their performance, which leads to increase productivity and budget management and improve the work environment and marketing processes for services and products, which is aimed at focusing on the use of modern technologies in the field of business. Brief We believe it will positively impact if implemented in the future and we will intensify future research in this area.

\section{REFERENCES}

[1]. Tirenni G., "Allocation of marketing resources to optimize customer equity," Ph.D. thesis, University of St. Gallen, Switzerland. 2005.

[2]. Labbi A., Berrospi C., "Optimizing marketing planning and budgeting using Markov decision processes: an airline case study", IBM Journal of Research and Development, vol. 51 Nos 3/4, pp. 421-431.2007.

[3]. Tirenni G., Abderrahim L., Cesar B., Andre E., Timir B., Kari P.,Seppo P., "Customer Equity and Lifetime Management (CELM) Finnair Case Study,” Marketing Science, vol.26 (4),pp.553-565, July .2007.

[4]. Todor R., " Blending traditional \& digital marketing," Bulletin of the Transilvania University of Brasov. Eco Science, vol.9(1), pp.51-56 2016.

[5]. Slater S., Stanley F., Eric M., "Factors influencing the relative importance of marketing strategy creativity and marketing strategy implementation effectiveness," Industrial Marketing Management ,vol.39,pp.551-59.2010

[6]. D. J. Earl and M. W. Deem., "Monte Carlo Simulations," Methods in Molecular Biology, vol. 443, pp. 25-36. 2006.

[7]. Webster, Frederick E., Jr. "The Changing Role of Marketing in the Corporation,” Journal of Marketing, vol.56, pp.1-17.October.1992.

[8]. Ekinci Y., Ulengin F., Uray N, and Ulengin B" Analysis of customer lifetime value and marketing expenditure decisions through a Markovianbased model," European Journal of Operational Research, vol.237(1),pp.278-288.2008.

[9]. Safari Kahre M., Tive M., Babania A., Hesan M.,"Analyzing the application of Customer Lifetime Value (CLV) based on benefit segmentation for the banking sector," Procedia - Social and Behavioral Sciences. $2^{\text {nd }}$ World Conference on Business, Eco and Management,2014, p. 590-4.

[10]. Pourmoayed R., L. R. and A. R. K.," A hierarchical Markov decision process modeling feeding and marketing decisions of growing pigs". European Journal of Operational Research,vol.250(3),pp.925-938.2016.

[11]. Hoey J., Schröder T., Alhothali A .,"Affect Control Processes:Intelligent Affective Interaction Using a Partially Observable Markov Decision Process." Artificial Intelligence,vol.230,pp.134-72.2016. 